\title{
Effectiveness of Teaching in Expressive Arts Therapy-Emotionally Traumatized Preschool Children
}

\author{
Chen I Ju ${ }^{1}$ \\ ${ }^{1}$ Teacher Education Center, Chaoyang University of Technology, Taiwan \\ Correspondence: Chen I Ju, Teacher Education Center, Chaoyang University of Technology, Taiwan. E-mail: \\ crissa@cyut.edu.tw
}

Received: February 20, 2014

Accepted: March 3, 2014 Online Published: May 26, 2014

doi:10.5539/ass.v10n12p195

URL: http://dx.doi.org/10.5539/ass.v10n12p195

\begin{abstract}
In recent years, the numbers of single parent families, skipped-generation education families and high-risk families are increasing year by year, and therefore, the proportion of preschool children from dysfunctional families are also increasing, wherein, these preschool children must face multiple pressures in the external environment, hence, it needs to pay special attention to life adjustment issues of these traumatized preschool children.
\end{abstract}

Kepner (1995) revealed that traumatic preschool childhood experiences coexisted with existing traumatic environments, while observing it from the viewpoint of development; preschool children's physical, mental and learning capabilities were completely affected. The primary system in the preschool childhood trauma cases was self-enclosed, supportless and helpless; thereby, they might find themself living in constant states of loneliness and hopelessness (Martin, 2009). If preschool childhood trauma was maintained over a considerable period, it could affect the personal development and self-functions as well as social relationships.

The cases of preschool children abuse are getting more and more due to the reasons of parental separations, bereavements, skipped-generation educations, witnessing acts of domestic violence; and in general, these preschool children desire to be loved, therefore, these traumatized preschool children will exhibit various degrees of life adjustment problems in different ways, and some of them may eager to show off their abilities, try to please others, and some are very quiet or cringe in front of others, some are very unstable, and some have aggressive tendencies, or have a lower level of learning motivation, or even, some are inveterate liars, etc. (McConnell, 2002).

The expressive arts therapy group introduced in this study aimed at older students of kindergartens affiliated to the elementary schools who belonged to emotionally traumatized preschool children with selective mutism and facing life adjustment problems. Thereby, all participants were asked to take part in 50-minute sessions of using expressive art media once a week for 10 weeks (10 unit activities in total). This study mainly aimed to explore the effectiveness of changes in the emotionally traumatized preschool children with selective mutism from high-risk families to participate in the expressive arts therapy group, particularly, the changes in their behaviors and emotions, and life adjustments.

This study used the self-created "Preschool Children's Emotional Life Adjustment Scale" to assess the performance of emotionally traumatized preschool children with selective mutism and had poor social life adjustments before and after the participation in the expressive arts therapy group; and wherein, class teachers were asked to assist the assessments in order to understand whether these traumatized preschool children had any improvement in life adjustments. In this study, the "Behavioral and Emotional Rating Scale (BERS)" revised by Yang, Zong-Ren (2001) and asked class teachers to assess the improvement of every preschool child's behavior and emotion, and life adjustment.

When these traumatized preschool children were participating in expressive arts therapy group to engage in artistic creations, in which, observing the creative process was a therapeutic tool, and moreover, the creation itself could often disclose new issues, and therefore, enhance preschool children's responsibility and interests of participation in these group; during the creative process, the preschool children's thinking would become more flexible (Rose, 2007). The changes in the process emphasized in this study meant the changes in behaviors of these traumatized preschool children conducted in the group in the process of engagement in the expressive arts 
therapy group.

Keywords: skipped-generation education families, high-risk families, loneliness and hopelessness, life adjustment

\section{The Definition of Expressive Arts Therapy}

The concepts of catharsis and sublimation in Freud's theory had a significant influence on the fields of education and psychology. However, Jung used the visual arts to carry out dialogue with the trauma, through active imagination, allowed research subjects to express their inner world as much as possible in order to achieve the intuitive self-healing (Evans \& Dubowski, 2001). For most people, the expressive arts therapy was remained in the stage of game projective tests, or often mistakenly thought that expressive arts therapy was a simple drawing analysis (Pink, 2006).

Except promoting broader mutual understanding among peoples, the process of art therapy can also contribute to our personal growth, rehabilitation and treatment (Bellini, 2006). Functions of art therapy, including visual thinking, feelings cannot express with language, emotional catharsis, and the creations of specific works. Through the creation of art works, it can evoke the hidden part of research subject, or ignored experience, etc. For these traumatized preschool children, expressive art activities just like playing games that are generally engaged in by spontaneous behaviors, therefore, therapists do believe that artistic activities are a very effective method in terms of the treatment of psychotherapy, or psychological counselling (Rubin, 2005).

\section{Relevant Theories of Expressive Arts Therapies}

\subsection{Arts Psychotherapy}

The art therapy was proposed by Margaret Naumburg in the early 1940s. Margaret Naumburg revealed that there were four advantages of art therapies in the orientation of psychological analysis, which comprised: the research subjects' general image expressions were Advantage to the language descriptions in the creative works, and paintings could directly express the inner experience that languages were difficult to clearly describe; and moreover, paintings could be used to project unconscious states of mind, reduce psychological defense, and then perform analytic treatments; each participant had absolute creative control over their piece at all times, and no matter how, their works would be accepted finally.

\subsection{Art as Therapy}

That concept of "Art as therapy" was introduced by Edith Kramer in about 1956. Edith Kramer's theory was related to basic concepts of psychoanalysis, but she simply stressed the essence of art theories, and proposed that the creative process itself had a specific effect of psychological treatments. She believed that artistic creation process could increase the individual's experience; during the creative process, inherent desires were be re-selected and re-classified by an Advantage will, in addition, internal conflicts will be re-experience, reintegration, and were resolved. Although the conflicts might not disappear completely, however, a large portion of conflicts could be satisfied with creative activities (Epp, 2008).

In the late 1950s, an American art educator-Viktor Lowenfeld who surveyed the theory of development of children picture in gang age stage and thus, launched a theory of "Stages of Artistic Development" based on Piaget's stage theory of cognitive development. As a result, it had not only laid a foundation of judging children's paintings, but also created a new model of arts therapies in education.

Although the orientation of two above mentioned theories seemed different, but both of them still focused on the creation of arts that was deemed an important element in the process of treatment. All painting skills in the process of treatment were not important at all, but instead, the psychological significance of research subject obtained in the process of creation was very important (Emery, 2004).

\section{Theories and Interpretations of Preschool Children's Paintings}

In many theories relating to children's paintings, Lowenfeld adopted concepts of Erikson's stages of psychosocial development and haptic-visualtheory to describe the developmental stages of children's paintings. In 1987, Lowenfeld \& Brittain classified the painting development into four stages: Scribbling stage (2-4 years), Preschematic stage (4-7 years), Schematic Stage (7-9 years), and Gang stage-Dawning Realist Stage (9-12 years). This theory of children's art developmental stages was the most popular theory used for interpreting the participants' paintings.

Any media, which can meet the specific requirements for children with special needs or can help children to express themselves, can be utilized properly. The materials used in the process of creation should contribute to the overall performance of preschool children, rather than to limit their capacities of original creations, it should 
be noted that some of complex production process may interfere with the willingness for creations of the preschool children.

When these traumatized preschool children are engaging in the expressive arts therapy activities, it must combine and focus on the importance of media materials, in which, these media materials not only will be able to maximize the advantage, and these preschool children will also learn to respect all the tools in this domain, for preschool children who are expecting to use these media materials, it must be suitable for the area of their personal development, coordinating their action level, previous experience, specific preferences, special needs, etc (Campbell, 1993). If media materials have sufficient diversity, these preschool children will disclose and develop their own unique preferences and tendency as well as the favorite patterns of expression. The biggest difference between the implementation of expressive arts therapy group and general counseling group lies in the creative expression and interpretation in the art therapy process.

\section{Discussion of Patterns of Expressive Arts Therapies}

Dalley (1984) generally partitioned it into two phases of "creative activity" and "sharing discussion". Additionally, the "creative activity" can use the expressive media materials to provide the participants to reflect themselves while experienced the feeling of being isolated, it can also increase the chances of interaction in the group through cooperation. Creation is an activity full of vigor and vitality that will bring good energy to both the individual and group.

Liebmann (1994) proposed that when using the expressive arts therapy group, the leader should focused on the application of group momentum method, in which, although art works could reflect the author's inner thoughts, but it was just a springboard only, the most important part was still discussions; the art work itself played a less important role, therefore, it almost spent no time to deeply explore art works itself, let all members of the group took turns to share their experience that would build a sense of group trust (American Psychiatry Association, 1994).

Through self-awareness and feedbacks from other members, the members may, therefore, realize their own behaviors and impacts caused to others; it might have some changes in the thinking and experience, and thus, be able to feedback to the group; even more, it could make more positive life changes of members outside the group and promote a more positive social interaction, thereby, enhancing self-esteem of members (Brooke, 2009). Members could understand themselves and others or otherwise, they could be understood by others through their art works; especially the recurring symbols, themes and subjects were a kind of deep and personal level of understanding and so being understanding. Participants sometimes were shocked by the messages conveyed by their own creations, and the reactions of other members could often inspire to personal self-explore.

Art creations within the group often can bring new perspectives to the creator itself and members of other group; artwork itself is actually the creator's statements, in a suitable moment, the interpretation of language can be added in order to achieve the interaction between creator and other members (McNamee, 2004). Making cyclic and mutual feedbacks through their own and others' eyes and frames, and then exploring the unknown future, which may not be understood by others, it may thus give yourself the opportunity to develop a more open mind, to promote the self-awareness and self-growth, so that changes in lives may hence occur.

The subjects in this study were preschool children, who were not able to express themselves sufficiently in any language; the program of expressive arts therapy used a variety of media materials to provide diversified and extensive applications and experiences. Paintings and other artistic activities were the main focus, in which, art works could project these traumatized preschool children's inner worlds, and help them to conduct self-awareness and released repressed emotions and psychological needs, which could conduct a dialogue with the inner self (Landreth, 2005). While they began to share and discuss their art works, the self-thought would be able to change slowly.

\section{Research Design}

In this study, the emotionally traumatized preschool children with selective mutism and facing life adjustment problems were chosen as the objects of research. Research designs included the use of various artistic media materials in the expressive arts therapy program to encourage these preschool children to conduct artistic creations; semi-structured programs were used in order to provide children with more space of independent development. Quantitative information included pre-test and post-test for group members' self-assessment in accordance with the "Preschool Children's Emotional Life Adjustment Scale", as well as the pre-test and post-test for assessing members made by the teachers based on the "Behavioral and Emotional Rating Scale (BERS)"; and in addition, this study would evaluate whether there was any difference in scores before and after 
the assessment. The qualitative data comprised data of interviews, the transcripts of qualification process, and analysis of members' art works.

\subsection{Design Concepts of Expressive Artistic Activities or Emotionally Traumatized Preschool Children}

The design related to expressive artistic activities conducted in this study was focused on the implementation of more structured activities to enhance the preschool children's sense of security for art therapy. The media materials adopted initially were with low complexity, structured media materials, so as to reduce the preschool children's psychological resistance and difficulty in the creative process. Later on, the creations using clays, fluid materials and wastes were added to the expressive artistic activities, in order to help these traumatized preschool children to release their emotions, and furthermore, to project and transform inner experience by means of new creative experiences.

The expressive artistic activities had been divided into three stages, the goal of first stage (primary and secondary times) was to establish a sense of security, in which, Topic: My favorite thing is ..., thereby, this activity aimed to create an atmosphere of trust and interaction in order to help these traumatized preschool children to release tense/anxious mood, so that they could pay attention to artistic creations. The goal of secondary stage (third to sixth times) was to demonstrate the preschool children's personal experience through artistic media materials, in which, Topic: The people whom I like is ..., thereby, it could encourage preschool children to freely express their feelings through artistic creations. The goal of third stage (seventh to tenth times) aimed at enhancing these preschool children's capabilities of emotional self-expression, Topic: I like my own ..., so as to enhance their self-appreciation.

\subsection{Backgrounds of Research Participants}

\subsubsection{Preschool Children}

Researcher understood the research subjects who participated in the expressive arts therapy group were preschool children from families of parental separations, bereavements, etc. Most of emotionally traumatized preschool children with selective mutism whom were introduced by their teachers exhibited various degrees of life adjustment problems in different ways, and some of them were marked by a lack of confidence, some were from dysfunctional families, and some were very quiet or cringe in front of others, some were very unstable, and some had a lower level of learning motivation, or even, some had emotional distress, or adverse relationships, etc. There were three research participants in total including two boys and one girl who were older students of kindergartens affiliated to the public elementary schools, wherein, research subjects were being labeled as B1, $\mathrm{B} 2$, and $\mathrm{B} 3$.

\subsubsection{Researcher}

To avoid the deviation of subjective awareness by the researcher while conducting expressive arts therapy activities, after the end of activities, various data collected should be cross examined, and researcher must continuously discuss it with different people (research subjects' teachers, parents, etc.) in order to clarify their viewpoints and findings.

\subsection{Research Tools}

Research tools used in this study included "Preschool Children's Emotional Life Adjustment Scale", "Behavioral and Emotional Rating Scale (BERS)", expressive artistic media materials, individual member's interview outline conducted after the activities, teachers' interview outlines, and parents' interview outlines. Furthermore, all data related to art therapy activities were gathered by means of recording, video and the transcripts of qualification process along with additional analyses and observations of subject's changes during overall sessions were to be used as a reference for the qualitative analysis and discussions of this study.

One week prior to implementation of activities, that is, on April 8, 2013, researcher had performed a pre-test to measure the self-assessment of these preschool children according to the "Preschool Children's Emotional Life Adjustment Scale"; and again, one week after the end of activities, that is, on June 21, 2013, researcher had also performed a post-test to measure the self-assessment of these preschool children in accordance with the "Preschool Children's Emotional Life Adjustment Scale", and the time interval between two tests was eleven weeks apart. The raw scores of pre-test and post-test in the "Preschool Children's Emotional Life Adjustment Scale" was listed as follows.

Based on the data of raw scores of pre-test and post-test in the "Preschool Children's Emotional Life Adjustment Scale", the preschool children's overall performance could be found as follows:

1) Scores of preschool children's overall performance: 
Based on the ten sub-scores of pre-test and post-test in the "Preschool Children's Emotional Life Adjustment Scale", it could be found that the ranking of most progressive in terms of adjustment, in the descending order, was "Social adaptation" (15 points), "Sense of adaptability" (13 points), "Life goals" (9 points), "Self-acceptance" (8 points), "Adjustment in study and play games" (7 points) and "Social skills" (7 points), "Affinity" (6 points) and "Behavioral maturity" (6 points), "Emotional stability" (4 points), "Mental endurance" ( 3 points); the percentage of overall adaptability of these three preschool children increased from $42 \%$ to $81 \%$, the higher scores were found in the "Social adaptation" and "Sense of adaptability", followed by "Life goals", "Self-acceptance" that had showed a significant improvement.

2) Scores of individual preschool children's performance:

After participating in expressive arts therapy activities, based on the ten sub-scores of pre-test and post-test in the "Preschool Children's Emotional Life Adjustment Scale", it could be found that performances of all three preschool children were progressive.

Supposed that increased 3 points in the sub-scores indicated a significant progress, then, "Affinity" was P3 (5 points); "Social skills" was P3 (5 points); "Social adaptation" was P2 (5 points); "Adjustment in study and play games" was P3 (4 points); "Life goals" was P1 (3 points), or P3 (3 points); "Sense of adaptability" was P2 (4 points); "Self-acceptance" was P3 (4 points).

There was a significant correlation in the overall emotional life adjustment for preschool children $(\mathrm{t}=-10.1, \mathrm{p}$ $<.01)$, and "Social adaptation" ( $\mathrm{t}=-5.06, \mathrm{p}<.05)$, "Behavioral maturity" $(\mathrm{t}=-3.70, \mathrm{p}<.05)$, "Sense of adaptability" ( $\mathrm{t}=-5.17, \mathrm{p}<.05)$, indicating that these three sub-scores had reached a statistically significant level; There were seven sub-scores of post-test were higher than that of pre-test, including: "Affinity", "Social skills", "Game adaptation", "Life goals", "Emotional stability", "Self-acceptance " and "Mental endurance", however, they still did not have a statistically significant difference.

From the above results, it can be found that the implementation of expressive arts therapy group can improve the emotional life adjustment for preschool children and it does have an immediate effect.

Based on the data of raw scores of pre-test and post-test in the "Behavioral and Emotional Rating Scale (BERS)", the preschool children's overall or individual performance could be found as follows:

1) Scores of preschool children's overall performance:

Based on the sub-scores of pre-test and post-test in the 'Behavioral and Emotional Rating Scale (BERS)", it could be found that performance of preschool children on the five sub-scores were progressive, and the ranking of most progressive in terms of parent-child relationship, in the descending order, was "Advantage interpersonal relationships" (52 points), "Advantage inherent abilities" (48 points), "Advantage emotions" (33 points), "Advantage family involvements" (29 points), "Advantage school achievements" (16 points). Statistical results demonstrated that there were four sub-scores of post-test were higher than that of pre-test, including: "Advantage interpersonal relationship", "Advantage family involvements", "Advantage inherent abilities" and "Advantage school achievements", however, they still did not have a statistically significant difference. The average score of total scales did not have a significant difference as well.

The average of percentile ranks of advantage emotional quotient of preschool children increased from $16 \%$ to $52 \%$, indicating that performances of preschool children's behavior and emotional adjustment were progressive. In which, "Advantage interpersonal relationships", "Advantage inherent abilities", and "Advantage emotions" had more significant improvements.

2) Scores of individual preschool children's performance:

After participating in expressive arts therapy activities, based on the five sub-scores of pre-test and post-test in the "Behavioral and Emotional Rating Scale (BERS)", it could be found that total scores of post-test of these preschool children were progressive. Among them, the ranking of most progressive in the post-test for these preschool children, in the descending order, was P3 (96 points), and the second was the P2 (48 points); followed by P1 (27 points).

Supposed that increased 3 points in the sub-scores indicated a significant progress, then, "Advantage interpersonal relationships" P3 (15 points); "Advantage family involvements" P3 (16 points); "Advantage inherent abilities" P3 (11 points); "Advantage school achievements" P1 (12 points), or P3 (8 points); "Advantage emotions" P2 (4 points), or P3 (9 points), so it could be found that the performance of individual preschool children was different, wherein, P1, P2, and P3 had significantly improved.

According to above research results, it had revealed that the implementation of expressive arts therapy group can 
improve the overall behavioral performance as well as emotional adaptation for these preschool children and it does have an immediate effect.

\section{Comprehensive Analysis of the Effectiveness of These Groups}

When comparing with various scores obtained from the "Emotional Life Adaptation Scale" and "Behavioral and Emotional Rating Scale (BERS)", it had disclosed that scores of post-test for preschool children were higher than that of pre-test. Wherein, the item of overall life adjustment has a significant improvement in the "Emotional Life Adaptation Scale", however, items of overall behavioral performance and emotional adaptation in the "Behavioral and Emotional Rating Scale (BERS)" does not have a significant improvement. The results of qualitative interviews demonstrate that after participating in expressive arts therapies for ten times, the adaptation of these preschool children in terms of life, behavior, and mood does have different levels of improvement.

\section{Changes in the Process of Participating in Expressive Arts Therapy Group}

With the assistance of these groups, researchers have successfully summarized the improvements and changes in the real-life activities for preschool children, including behaviors, moods, interpersonal relationships, and learning conditions.

\subsection{Emotional Stability}

Some hyperactive and impulsive children are not easy to get angry, losing their tempers, or crying; they will be able to calm themselves down; they can accept other people's opinions and become more responsible, they will not shift responsibility for themselves to others again; children suffer from low self-confidence begin to change in their expression with more diversified languages.

\subsection{Become a More Proactive}

These preschool children will take the initiative to help other kids and try to be teacher's little helpers. When returning to their homes, these children would like to help family members to share the household chores.

\subsection{Peer Relationships}

Whenever it is necessary, children with low self-confidence will actively ask the other children to provide support and assistance in the group; they can appear more "cheerful" looking, situations have a lot of improvement, and it can also help improve their peer relationships.

\subsection{Learning Attitude}

In the class, they will actively raise their hands to respond teacher's questions; they will try to express their viewpoints, to complete the study quicker than before, and show a positive attitude towards learning.

According to results of qualitative interviews, it can be found that emotionally traumatized preschool children with selective mutism exhibit positive feelings in the aspects of emotional stability, social interaction, learning, and emotional expressions.

\section{Suggestions for Future Researches}

\subsection{Research Topics}

This study finds those expressive arts therapy groups are very suitable for these traumatized preschool children and has an immediate effect of counseling. While interviewing with parents, researcher found that it is worth paying attention to parenting education issues, the children's problems are usually derived from the their families, the future researches may try to conduct expressive arts therapy activities for the parent-children or whole family members in order to explore its effects.

\subsection{Teacher Training}

Teachers need to study more substantial knowledge of grief counseling in order that they can help students to enhance their abilities to overcome difficulties in their lives, to reduce emotional distress with better skills for settling life adjustment problems. In addition, there are two must-have capabilities for an expressive arts therapist which comprise art creations and psychotherapy, If schools can focus on the programs of teacher training, providing teachers with training programs of art therapy or credit classes, the promotion of expressive arts therapy will be a great help to school counseling works, no matter if it is being applied to the individual case or group. 


\section{References}

American Psychiatry Association. (1994). Quick Reference to the Diagnostic Criteria. Washington, D. C.: American Psychiatry Association.

Bellini, S. (2006). Building social relationships: A systematic approach to teaching social interaction skills to children and adolescents with autism spectrum disorders and other social difficulties. Shawnee Mission, KS: Autism Asperger Pub. Co.

Brooke, S. L. (2009). Introduction-Video Modeling. In S. L. Brooke (Ed.), The Use of Creative Therapies with Autism Spectrum Disorders (pp. 3-17). Springfield: Charles C Thomas.

Campbell, J. (1993). Creative Art in Group work. Bicester: Speech mark.

Dalley, T. (Ed.). (1984). Art as therapy: An introducing to the use of as a therapeutic technique. London: Tavistock/New York: Methuen. http://dx.doi.org/10.4324/9780203325186

Emery, M. J. (2004). Art therapy as an intervention for autism. [Peer Reviewed]. Art Therapy, 21(3), 143-147. http://dx.doi.org/10.1080/07421656.2004.10129500

Epp, K. M. (2008). Outcome-Based Evaluation of a Social Skills Program Using Art Therapy and Group Therapy for Children on the Autism Spectrum. Children \& Schools, 30(1), 27-36. http://dx.doi.org/10.1093/cs/30.1.27

Evans, K., \& Dubowski, J. (2001). Art therapy with children on the autistic spectrum: Beyond words. Philadelphia, PA: Jessica Kingsley Pub.

Kepner, J. (1995). Healing Tasks: Psychotherapy with Adult Survivors of Childhood Abuse. Gestalt Institute of Cleveland, Jossey Bass Publishers, San Francisco.

Landreth, G. L. (2005). Play therapy interventions with children's problems: Case studies with DSM-IV-TR diagnoses (2nd ed.). Lanham: Jason Aronson.

Liebmann, M. (2004). Art therapy for group: a handbook of themes and exercises (2nd ed.). Hove, East Sussex: Brunner-Routledge.

Martin, N. (2009). Art as an early intervention tool for children with autism. London: Jessica Kingsley.

McConnell, S. R. (2002). Interventions to facilitate social interaction for young children with autism: Review of available research and recommendations for educational intervention and future research. Journal of Autism and Developmental Disorders, 32(5), 351-372. http://dx.doi.org/10.1023/A:1020537805154

McNamee, C. M. (2004). Using both sides of the brain: Experiences that integrate art and talk therapy through scribble drawings. Journal of the American Art Therapy, 21(3), 136-142. http://dx.doi.org/10.1080/07421656.2004.10129495

Pink, S. (2006). Doing Visual Ethnography: Images, Media and Representation in Research (2nd ed.). London: Sage.

Rose, G. (2007). Visual methodologies (2nd ed.). London: Sage.

Rubin, J. A. (2005). Child art therapy (25th anniversary ed.). Hoboken, N.J.: John Wiley.

\section{Copyrights}

Copyright for this article is retained by the author(s), with first publication rights granted to the journal.

This is an open-access article distributed under the terms and conditions of the Creative Commons Attribution license (http://creativecommons.org/licenses/by/3.0/). 